\title{
Evaluation of Virucidal Activity of Residual Quaternary Ammonium- treated Surfaces on SARS-CoV-2
}

\author{
Alex Caschera MSc ${ }^{a}$, Julie McAuley $\mathrm{PhD}^{\mathrm{b}}$, Youry Kim $\mathrm{PhD}^{\mathrm{b}}$, Damian Purcell $\mathrm{PhD}^{\mathrm{b}}$ \\ Jasper Rymenants MEng ${ }^{c}$, Daniel A. Foucher PhD ${ }^{\text {** }}$ \\ ${ }^{a}$ Ryerson University, Department of Chemistry and Biology; 350 Victoria St., Toronto, \\ Ontario, Canada, M5B 2K3 \\ ${ }^{b}$ Department of Microbiology and Immunology, The University of Melbourne at the Peter \\ Doherty Institute for Infection and Immunity, Melbourne, VIC, Australia \\ c Laboratory of Virology and Chemotherapy Rega Institute for Medical Research \\ Herestraat 49 postbus 1043, Leuven, Belgium
}

\begin{abstract}
Background: The COVID-19 pandemic has had an unprecedented impact on global health and the world's economies. The recent proliferation of SARS-CoV-2 variants, that appear to be far more communicable and virulent in terms of morbidity and mortality, requires new and more effective transmission mitigation strategies. Under the right environmental conditions and with good quality standardized sampling protocols, culturable and infectious SARS-CoV-2 has been shown to survive on contaminated fomites (inanimate surfaces and objects) from hours to months. Surface stability is enhanced in the presence of a soil load (saliva, blood, feces) and favored by indoor and cold environments. In the present study we evaluated a surface-anchored polymeric quaternary ammonium antimicrobial that can be applied commercially to high touch surfaces as a preventative measure, to help reduce the potential risk of fomite transmission of SARS-CoV-2 from contaminated surfaces. Antimicrobial surface treatments were prepared in our laboratory in March 2020 and evaluated against two isolates of SARS-CoV-2 (hCoV-19/Australia/VIC01/2020, hCoV-19/Belgium/GHB03021/2020) in April 2020.
\end{abstract}

Methods: Two studies were performed on metal disks, pre-treated with a surface-coating of organofunctional silane polymeric antimicrobial, by two independent BSL 3 equipped laboratories. These facilities were in Belgium (the Rega Medical Research Institute of KU Leuven, Belgium) and the other in Australia (the Peter Doherty Institute for Infection and Immunity in Melbourne, Australia) and independently applied quantitative carrier-based methodologies (without mechanical wear) using the authentic SARS-CoV-2 isolates from patients. 
Results: Under residual dry conditions against representative stainless-steel control surface carriers, the tests which were independently conducted at both facilities demonstrated a sustained antiviral effect imparted from the antimicrobial surface treatments by SARS-CoV-2 virion destruction (108.23 TCID50/carrier GHB-03021 isolate, and $10^{3.66} \mathrm{TCID}$ 50/carrier VIC01 isolate) 10 minutes after the 1-hour contact time required for virus drying. These reductions are further supported by degradation of the RNA genetic material indicating viral deactivation on antimicrobial-treated surfaces by qRTPCR.

Conclusions: A commercially available and EPA/PMRA registered quaternary ammonium antimicrobial formulation was applied to stainless steel carrier disks and sent to two virology research institutes to independently determine whether samples treated with SiQAC-C18 antimicrobial material could deactivate deposited SARS-CoV-2 virions on contaminated surfaces. The results independently support a sustained antiviral effect imparted from these treated surfaces by both SARS-CoV-2 virion destruction and degradation of viral RNA. These preliminary results indicate the SiQAC-18 treated surfaces could play an important role in mitigating the communicability and fomite transmission of SARS-CoV-2.

Keywords: Bacteria, SARS-CoV-2, Self-disinfecting Surface, Efficacy, Frequently Touched Environmental Surfaces, Coronavirus, Biocidal Treatment, Fomite Spread

\section{Introduction}

Throughout the current pandemic, a severe respiratory tract infection in humans resulting from the SARS-CoV-2 coronavirus spread by aerosol droplets[1] from infected persons, and fomites on common touch surfaces have both been confirmed indirectly [2] as key vectors of transmission (Figure 1).[3] In the later instance, the persistence of the SARS-CoV-2 on inanimate surfaces has been documented up to three days[4], and up to 20 days in cooler environments, [5] such as those found in meat packing plants.[6] The SARS-CoV-2 virus is a zoonotic virus, likely spread from bats to live wet markets in China,[7] and transmitted to humans.[8] While the projected infection mortality rate of this virus (0.4\%-3.6\%)[9] is lower than other more recent infectious viruses such as H5N1 influenza A virus (60\%), MERS-V-CoV (34-36\%) and Ebola (41\%), the more transmissible SARS-CoV-2 has been confirmed to have infected over 150 million individuals worldwide as of May 2021.[10,11,12] At this time, human-to-human SARS-CoV-2 infections caused by airborne or fomite transmission have exponentially risen with qRT-PCR cyclethreshold values (>33-34 for the $\mathrm{N}$ gene of SARS-CoV-2) known to produce a high rate of both false positive and false negative results, with over 3.1 million reported deaths.[12] 


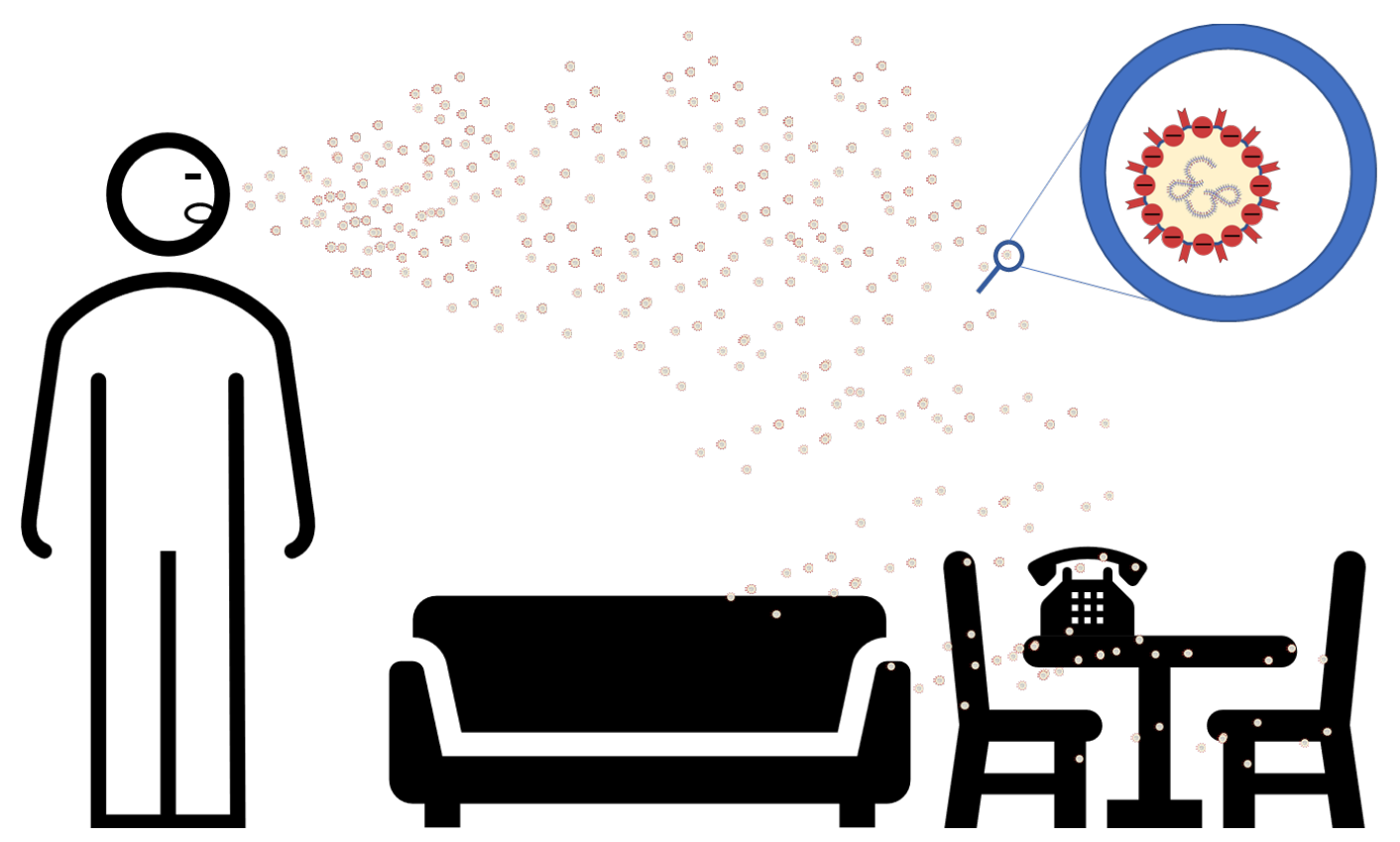

Figure 1 Fomite transmission can occur from contact with surfaces contaminated with virion-containing water droplets, produced via coughing or sneezing by an infected individual.

While the implementation of lockdowns, social distancing and mask mandates has stemmed viral spread in most jurisdictions, COVID-fatigue and economic decline have taken their toll. Hospitals, clinics, long-term/senior care facilities and institutions such as schools, nursing homes and prisons have been on the frontlines of the SARS-CoV-2 pandemic. Due to the aerosol nature of the virus, transmission from human to human via droplets or from contaminated surfaces, innovative mitigation and preventative approaches must be adopted. Current virus control has been carried out in part through the implementation of stringent cleaning protocols of all touch surfaces with traditional quaternary ammonium compounds,[13] bleach, stabilized chlorine dioxide, hydrogen peroxide, alcohols and other disinfectants as well as UV exposure.[14,15] While these biocidal chemicals and physical (UV, autoclave, etc.) treatments are effective at momentarily disinfecting surfaces of infectious virions, they do not render them antiviral after treatment.

Since surface-anchored, C18 quaternary ammonium antimicrobials (SiQAC-C18) are known to disrupt phospholipid membranes in bacteria and fungi, it has been previously theorized that a similar mechanism could work to de-protect viruses within the Coronaviridae family, ultimate leading to viral deactivation.[16-18] There is also additional evidence that quaternary ammonium antimicrobials are effective at deactivating other respiratory viruses.[19,20] The preventive role of fixed quaternary ammonium antimicrobials on hard or porous surfaces to kill and prevent the buildup of microbial pathogens and biofilms has been well established against both gram-positive and gram- 
negative bacteria in our research group.[21,22] Surface-anchored C18 quaternary ammonium cations to metals, plastics and glass materials have also been extensively studied and have been demonstrated to be effective in killing on contact.[23,24]

Antiviral agents for use on inanimate surfaces have been the subject of research and commercial activities since the 1950s, however only a few successful antiviral studies have been undertaken with coatings made with these materials on treated surfaces. Tsao et al first demonstrated the (SiQAC-C18) polymerized onto alginate beads could remove viruses from pharmaceutical solutions and proposed a mechanism of inactivation.[16] A decade later a silane coated sand filter was shown to reduce non-enveloped viruses in water filtration applications.[25] Testing data also supports susceptibility of enveloped influenza virus organisms to the active ingredient in the commercial product tested on glass,[17] plastic[19] and cotton surfaces[20]. More recently, a continuously active antimicrobial coating has been effective at deactivating human coronavirus $229 \mathrm{E}$, an related viral strain within the SARS-CoV-2 family.[26]

SARS-CoV-2 is an enveloped, non-segmented, positive sense RNA virus with a diameter of $65-125 \mathrm{~nm}$, containing single strands of RNA and provided with crown-like spikes on the outer surface. The envelope is formed from the phospholipid membranes of host cells and serves to protect the virions from degradation.[27,28] We hypothesized that quaternary ammonium antimicrobial, an agent that is able to destabilize phospholipid membranes, could be used as a protective coating that would render SARS-CoV-2 noninfectious.

To investigate the efficacy of quaternary ammonium antimicrobials as antiviral coatings, a commercially available quaternary ammonium antimicrobial treatment was applied to stainless steel carrier disks and sent for evaluation against two distinct SARSCoV-2 isolates. The results from these tests demonstrate evidence of an antiviral effect imparted from these coatings and potential use as a long-lasting antiviral surface treatment.

\section{Materials and Methods:}

\section{Carrier Surface Preparation:}

Sample carriers consisted of treated and control stainless steel $(2 \mathrm{~cm}, 2 \mathrm{~B}$ finish) disks, kindly donated by Pegan Industries. At Ryerson University, Toronto, Canada carriers were pre-sorted, pre-cleaned per EN16777:2018,[29] and pre-dried by storing in an $80^{\circ} \mathrm{C}$ oven until use. All microbiological operations were performed using aseptic techniques. To reduce variation between carrier treatments, which were handled inside a type A2 biosafety cabinet, the individual carriers with the designated to be treated side up were placed into individual sterile Petri dishes lined with sterile filter paper to absorb overspray and with the lids opened. The formulated organofunctional silane SiQAC-C18 
product was applied by a commercial sprayer until thoroughly wetted: For samples provided to the Doherty Institute, the SiQAC-C18 product was applied using an air brush sprayer, distance of $20 \mathrm{~cm}$ at a $45^{\circ}$ angle, $50 \mu \mathrm{L}$ application volume per carrier, and the Rega Institute via an electrostatic sprayer, distance of 2 feet, 10 seconds spray time, 50 $\mu \mathrm{L}$ application volume). Surface carriers were either pre-treated with the antimicrobial test substance or left as untreated controls. Immediately after treatment, samples were transferred from Ryerson University to the Rega Institute at KU Leuven (S1) and the Doherty Institute at the University of Melbourne $(\mathrm{S} 2, \mathrm{~S} 3)$ for efficacy testing. Testing was performed 46 and 47 days respectively after the carrier were treated.

\section{Cytotoxicity}

Cytotoxicity of SiQAC-C18 active antimicrobial were performed on host monolayer cell lines (VERO cells; ATCC \#CCL-18 for VIC01, ATCC \#CRL-1586 for GHB-03021) without virus. This was accomplished by subjecting host monolayer cells with $50 \mu \mathrm{L}$ of SiQAC-C18, following the TCID 50 protocol described above.

\section{SARS-CoV-2 Test Isolates}

The SARS-CoV-2 isolates used in this study were independently isolated and cultured by the Doherty Institute (Victoria, Australia) [30] and Rega Institute [31]. At the Doherty Institute, stocks of SARS-CoV-2 isolate hCoV-19/Australia/VIC01/2020 (VIC01) [3] was produced as previously described [4] and was within 2 passages of the original cultured patient isolate and sequence confirmed to match the publicly available genome data. Titres of the VIC01 isolate stocks was determined to be $10^{5.73} \mathrm{TCID}{ }_{50} / \mathrm{mL}$. The Rega Institute SARS-CoV-2 isolate hCoV-19/Belgium/GHB-03021/2020 (GHB-03021) was produced as described [31] and used within 42 passages and the stock titre determined to be $10^{8.24} \mathrm{TCID} 50 / \mathrm{mL}$.

\section{Carrier Surface Efficacy Test}

A $50 \mu \mathrm{L}$ viral suspension of SARS-CoV-2 patient isolate was inoculated (with soil load for GHB-03021) onto a $2 \mathrm{~cm}$ surface of control and SiQAC-C18 coated stainless steel carriers (VIC01 $n=4$, GHB-03021 $n=3$ ) and incubated at $20 \pm 1{ }^{\circ} \mathrm{C}$ for the contact time. The control and treated carriers were inoculated with $50 \mu \mathrm{L}$ viral stocks of $10^{6.91}$ (GHB-03021) and 104.00 (VIC01), respectively. After 10 minutes past each 1-hour drying period, antiviral material on the carrier samples was removed by rinsing with a select recovery media with vigorous pipetting to further recover remaining infectious viruses from the surface. Appropriate 1:10 dilutions of recovered control and test samples were plating onto monolayers prepared and performed as described.[4,31] The collected sample rinse media was assayed for infectious virus concentration by a cell culture-based viral infectivity assay (TCID 50 assay) [30][31]. The amount of infectious virus was 
compared to that from the coated control carrier to determine the efficacy of the coating by the viral reduction by the treated carrier.

\section{qRT-PCR Test}

$140 \mu \mathrm{L}$ of sample of VIC01 virions was immediately added to AVL buffer for 10 min, then $100 \%$ ethanol to initiate RNA extraction for qRT-PCR analysis. The samples were removed from a BSL 3 facility and the RNA purification was completed using the QiaAmp Viral RNA mini kit in the BSL 2 facility. RNA was stored at $-80^{\circ} \mathrm{C}$ until processed via $\mathrm{qRT}$-PCR. To evaluate the amount of virus genome present in each sample, a quantitative reverse-transcription PCR (qRT-PCR) for detection of the SARS-CoV-2 envelope (E) gene was performed using the SuperScript III OneStep qRT-PCR System with Platinum_ Taq DNA Polymerase (Invitrogen, Carlsband, CA, USA). The qRT-PCR assay was performed on a Bio-Rad CFX96 Touch Real-Time PCR Detection System (Bio-Rad, Hercules, CA, USA) using the following conditions: a denaturation step at 55 ${ }^{\circ} \mathrm{C}$ for $10 \mathrm{~min}$ and $95^{\circ} \mathrm{C}$ for $3 \mathrm{~min}$, followed by 45 cycles of amplification $\left(94{ }^{\circ} \mathrm{C}\right.$ for $15 \mathrm{~s}$ and $58{ }^{\circ} \mathrm{C}$ for $30 \mathrm{~s}$ ). A known amount of SARS-CoV-2 RNA (generated previously from virus stock cultures) diluted twofold was used to generate a standard curve. The $\mathrm{Ct}$ values from the standard curve were used to interpolate the amount of SARS-CoV-2 RNA in each sample.

\section{Results:}

To test the cytotoxicity of SiQAC-C18, we exposed undiluted solution to Vero and Vero E6 cells, which are the cell lines used for SARS-CoV-2 propagation and quantitation for infectious titre. We found that there was a negligible amount of cell death on the respective cell monolayers (S1, S2). As such, any leaching of SiQAC-18 during the washing and sample elution phase was determined to not induce detrimental effects on the cell monolayer. Thus, any cytopathic effects observed in sample eluates when quantitating the remaining infectious titre by conducting a $50 \%$ Tissue Culture Infectious Dose (TCID 50 ) assay could be attributed to by presence of infectious virus and not cytotoxic effects of the SiQAC-C18 compound.

The ability for SiQAC-C18 to render SARS-CoV-2 non-infectious, was then examined by performing the carrier surface efficacy test. Combined data from studies performed on GHB-03021 and VIC01 isolates is shown in Figure 2. Data was collected and processed using the Reed-Muench method and was calculated to determine the viral load within the collection media. For the GHB-03021 isolate, a reduction of $10^{2.93}$ was determined $\left({ }^{*} p=0.0014\right.$ compared to control, unpaired t test, $n=3$ ). While, for the VIC01 isolate there was no detectable infectious virus present, indicating a more than $10^{3.38}$ reduction in infectious titre when samples were exposed to SiQAC-C18 $\left({ }^{* * *} p<0.0001\right.$ compared to control, unpaired $t$ test, $n=4$ replicates). 


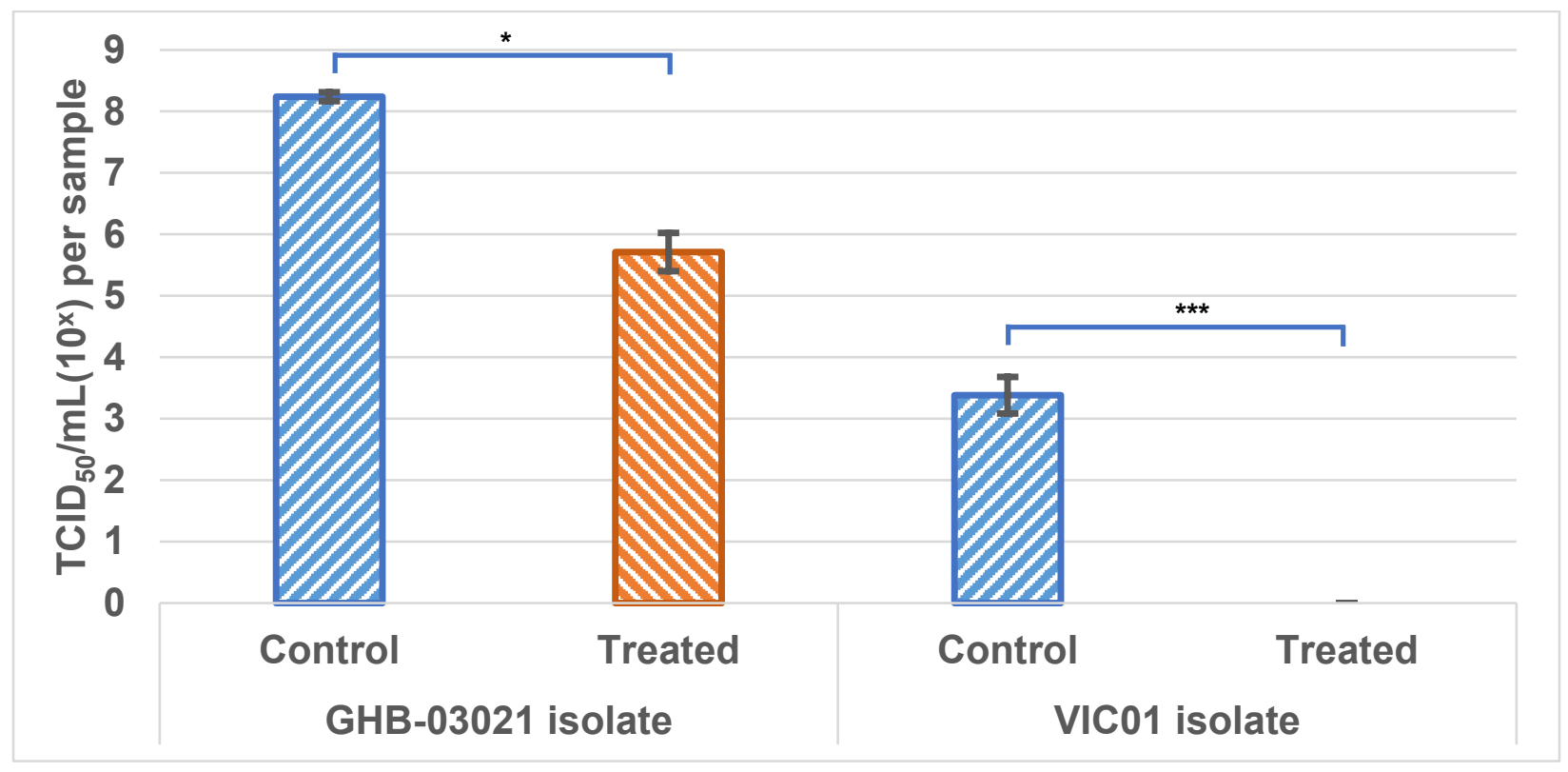

Figure 2 - The carrier surface test was used to evaluate the antiviral activity against SARS-CoV-2 isolates GHB-03021 and VIC01. The treated surfaces for each isolate were prepared by two different methods. An electrostatic sprayer applied SiQAC-C18 to surfaces used for the GHB-03021 exposure, while product was applied using an air brush sprayer for samples exposed to VIC01. After drying and a further contact time of $10 \mathrm{~min}$, surfaces were washed, eluate collected and remaining infectious virus titre determined by a TCID 50 assay.

We next evaluated whether exposure of SARS-CoV-2 to the SiQAC-C18 product could degrade virus genome in addition to reducing the infectious virus titre. To do this, at the same time as collecting samples from the SiQAC-C18 and untreated control exposed VIC01 isolate, an aliquot was processed to extract virus genome. We then performed a quantitative real-time PCR reaction to determine the amount of intact virus Envelope $(E)$ gene present in the sample. Figure 3 reveals that for virus exposed to the SiQAC-C18 product, the genome was significantly degraded, with $>10^{7}$ less intact $E$ gene detected compared to VIC01 exposed to the untreated disc (control). These results indicate that the viricidal activity of SiQAC-C18 disrupts the viral membrane and either the exposure of the viral RNA to the environment leads to natural degradation, or that the surface treatment can directly degrade the virus genome. 


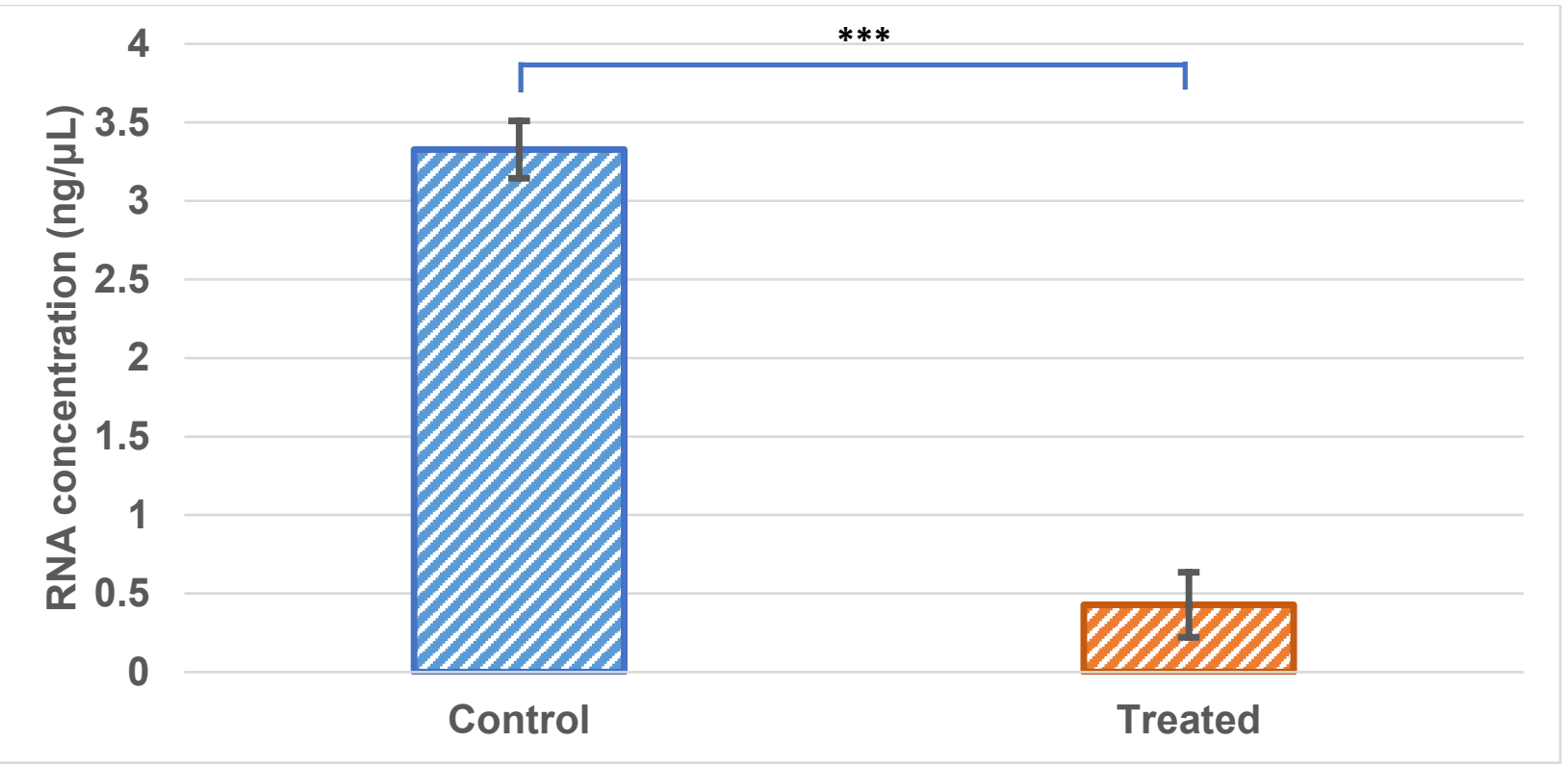

Figure 3 - qRT-PCR data from the VIC01 isolate study. RNA was extracted from eluate samples, then assessed for intact $E$ gene via quantitative RT-PCR. ${ }^{* * *} p<0.0001$ for unpaired $t$ test across 4 replicates.

\section{Discussion:}

Our study reveals that SiQAC-C18 is highly viricidal against SARS-CoV-2. Importantly, as the carrier surface tests were conducted more than 40 days post-addition of the coating to the surface, then internationally transported to each institute for testing, the robustness of the findings of SiQAC-C18 viricidal activity against SARS-CoV-2 is significant. Further adding to the effectiveness of the SiQAC-C18 product, slightly different methodologies were employed and used two geographically distinct SARS-CoV2 isolates. Analysis of the published genome sequence data for spike protein, which is the major virion surface glycoprotein involved with cellular attachment and infection, revealed only 1 amino acid difference between the VIC01 and GHB-03021 isolates, with the GHB-03021 isolate matching the original Wuhan sequence.[32] This genome sequence data reveals that the viruses used by our study, despite being isolated from infected humans in geographically distinct locations were closely related. However, the VIC01 SARS-CoV-2 was tested within 2 passages of the original cultured patient isolate, while the GHB-03021 had been passaged in cells more than 40 times and likely may have obtained evolutionary changes resulting in altered viral fitness. This postulation is supported by the fact that there was an $\sim 10^{2.5}$ increase in stock titre of the GHB-03021 virus compared to the $\mathrm{VICO} 1$ isolate. Thus, in addition to the coating techniques on the stainless steels surface, these potential differences in SARS-CoV-2 fitness, could have theoretically impacted the viricidal activity of the SiQAC-C18 surface coating. It is therefore noteworthy that both institutes independently revealed SiQAC-C18 exhibits viricidal activity against SARS-CoV-2. These findings are in agreement with previous data 
that demonstrated antiviral activity of SiQAC-C18 active is independent of the coating substrate (plastic, glass, and textiles), and the type of enveloped virus or variant.[19,20]

A viral load between $10^{4.8}-10^{6.3}$ per carrier (as indicated by the plate recovery control challenge) is the dose recommended for inoculation to determine antimicrobial activity of disinfectants against viruses dried on surfaces (ASTM E1053)[33] and on fingerpads cleaned with handrub agents (ASTM E1838).[34] Inoculums added to each carrier were slightly higher (GHB-03021 isolate), or slightly lower (VIC01 isolate) than recommended, but testing revealed $>10^{3}$ reduction compared to untreated controls, regardless of infectious dose added to the treated and untreated discs. We postulate that the reduction in infectious titre indicates that the SiQAC-C18 product may have rendered SARS-CoV-2 non-infectious, either by altering the ability for the virion to attach and infect the cell by changing surface glycoprotein structures, or by causing virion membrane lysis and degradation. Given that the QRT-PCR analysis performed on the VIC01 isolate revealed degradation of viral genomic material when exposed to the antimicrobial coated surface, it is likely that structures integral to virion integrity, such as the viral envelope of SARS-CoV-2 are damaged following contact with a SiQAC-C18 functionalized surface (Figure 4). Following this, the SiQAC-C18 product either then continued act directly on the RNA genome, or environmental exposure induced degradation of the viral RNA.

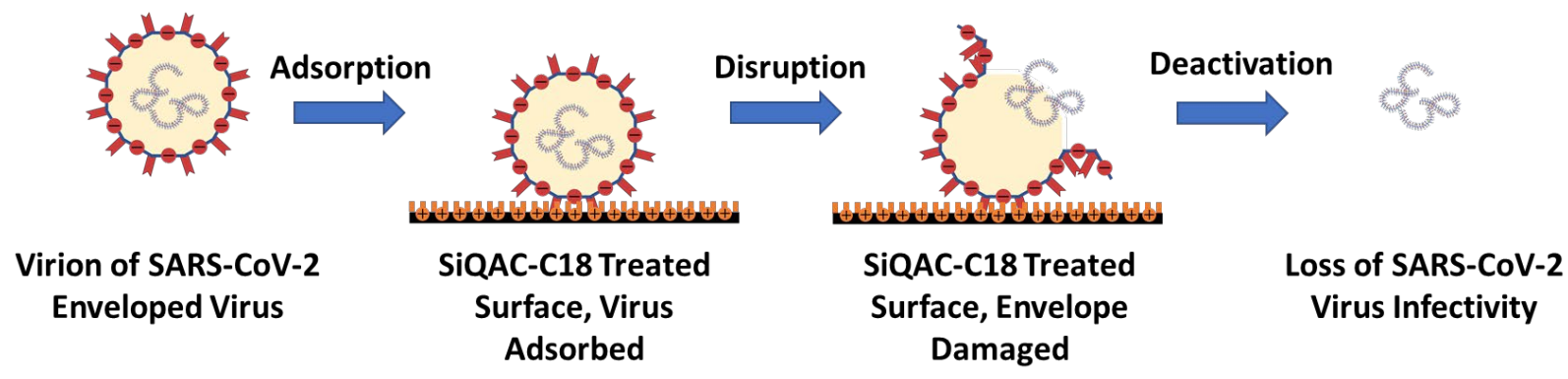

Figure 4 Proposed mechanism of enveloped virus deactivation by SiQAC-C18 treated surface demonstrating adsorption, disruption and deactivation of virion particles.

In alignment with our current findings of SiQAC-C18 antiviral activity, antimicrobial organofunctional silane coatings have been demonstrated to reduce SARS-CoV-2 isolates on treated surfaces. While our study demonstrated the antiviral activity of SiQACC18 on non-porous metal coupons, we expect a similar efficacy to be achieved on a variety of porous and non-porous surfaces including textiles, glass, furniture, and plastics found in hospitals, transit, and other public settings, similar to the antimicrobial results observed quaternary ammonium treated surfaces.[21,35]

* Address correspondence to Daniel Foucher, PhD. Department of Chemistry and Biology, Ryerson University, Toronto, ON, Canada M5B 2K3.

E-Mail address: daniel.foucher@ryerson.ca 
Supplementary Material: Raw data reports from the Riga Institute (S1) and the Doherty Institute (S2, S3) are available here.

Acknowledgement: The authors would like to thank Dr. Curt White and Dr. Lukasz Porosa for their help in preparing the (SiQAC-C18) treated samples at Ryerson University and supplying the raw data. We would also like to thank Dr. Costin Antonescu and Dr. Joseph McPhee from Ryerson for their careful review and edits of this manuscript, and Dave Wilkins for facilitating communication between Ryerson, the Rega and Doherty Institutes.

Role of the Funder: The virology research in this study was funded by ViaClean Technologies Inc. who supported testing for the SARS-CoV-2 trials in Australia and Belgium. The results of these trials were shared with Foucher and Caschera. Foucher and Caschera received no compensation from any party for their efforts in preparing and submitting a manuscript.

\section{References:}

[1] Lednicky JA, Lauzardo M, Fan ZH, Jutla A, Tilly TB, Gangwar M, et al. Viable SARS-CoV-2 in the air of a hospital room with COVID-19 patients. Int $\mathrm{J}$ Infect Dis 2020;100:476-82.

[2] Bedrosian N, Mitchell E, Rohm E, Rothe M, Kelly C, String G, et al. A systematic review of surface contamination, stability, and disinfection data on SARS-CoV-2 (through July 10, 2020). Environ Sci Technol 2020. https://doi.org/10.1021/acs.est.0c05651.

[3] Jayaweera M, Perera H, Gunawardana B, Manatunge J. Transmission of COVID19 virus by droplets and aerosols: A critical review on the unresolved dichotomy. Envronmental Res 2020;188:1-18.

[4] van Doremalen N, Bushmaker T, Morris DH, Holbrook MG, Gamble A, Williamson BN, et al. Aerosol and Surface Stability of SARS-CoV-2 as Compared with SARSCoV-1. N Engl J Med 2020;382:1564-7. https://doi.org/10.1056/NEJMc2004973.

[5] Riddell S, Goldie S, Hill A, Eagles D, Drew TW. The effect of temperature on persistence of SARS-CoV-2 on common surfaces. Virol J 2020;17:1-7. https://doi.org/10.1186/s12985-020-01418-7.

[6] Günther T, Czech-Sioli M, Indenbirken D, Robitaille A, Tenhaken P, Exner M, et al. SARS-CoV-2 outbreak investigation in a German meat processing plant. EMBO Mol Med 2020;12:1-10. https://doi.org/10.15252/emmm.202013296.

[7] Burki T. The origin of SARS-CoV-2. Lancet Infect Dis 2020;20:1018-9. https://doi.org/10.1016/S1473-3099(20)30641-1.

[8] Spiteri G, Fielding J, Diercke M, Campese C, Enouf V, Gaymard A, et al. First cases of coronavirus disease 2019 (COVID-19) in the WHO European Region, 24 January to 21 February 2020. Euro Surveill 2020;25:95-104. 
https://doi.org/10.2807/1560-7917.ES.2020.25.9.2000178.

[9] Verity R, Okell LC, Dorigatti I, Winskill P, Whittaker C, Imai N, et al. Estimates of the severity of coronavirus disease 2019: a model-based analysis. Lancet Infect Dis 2020;20:669-77. https://doi.org/10.1016/S1473-3099(20)30243-7.

[10] Petersen E, Koopmans M, Go U, Hamer DH, Petrosillo N, Castelli F, et al. Comparing SARS-CoV-2 with SARS-CoV and influenza pandemics. Lancet Infect Dis 2020;20:e238-44. https://doi.org/10.1016/S1473-3099(20)30484-9.

[11] Reiner RC, Barber RM, Collin JK, Zheng P, Adolph C, Albright J, et al. Modeling COVID-19 scenarios for the United States. Nat Med 2021;27:94-105. https://doi.org/10.1038/s41591-020-1132-9.

[12] La Scola B, Le Bideau M, Andreani J, Hoang VT, Grimaldier C, Colson P, et al. Viral RNA load as determined by cell culture as a management tool for discharge of SARS-CoV-2 patients from infectious disease wards. Eur J Clin Microbiol Infect Dis 2020;39:1059-61. https://doi.org/10.1007/s10096-020-03913-9.

[13] Ogilvie BH, Solis-Leal A, Lopez JB, Poole BD, Robison RA, Berges BK. Alcoholfree hand sanitizer and other quaternary ammonium disinfectants quickly and effectively inactivate SARS-CoV-2. J Hosp Infect 2021;108:142-5. https://doi.org/10.1016/j.jhin.2020.11.023.

[14] Khalid ljaz M, Sattar SA, Rubino JR, Nims RW, Gerba CP. Combating SARSCoV-2: leveraging microbicidal experiences with other emerging/re-emerging viruses. PeerJ 2020;8:1-24. https://doi.org/10.7717/peerj.9914.

[15] Rutala WA, Weber DJ. Guideline for Disinfection and Sterilization in Healthcare Facilities, 2008. vol. 18. 2019.

[16] Tsao I-F, Wang HY, Shipman C. Interaction of infectious viral particles with a quaternary ammonium chlorid (QAC) surface. Biotechnol Bioeng 1989;34:639-46. https://doi.org/10.1002/bit.260340508.

[17] Tuladhar E, de Koning MC, Fundeanu I, Beumer R, Duizer E. Different virucidal activities of hyperbranched quaternary ammonium coatings on poliovirus and influenza virus. Appl Environ Microbiol 2012;78:2456-8. https://doi.org/10.1128/AEM.07738-11.

[18] Shirai J, Kanno T, Tsuchiya Y, Mitsubayashi S, Seki R. Effects of Chlorine, lodine, and Quaternary Ammonium Compound Disinfectants on Several Exotic Disease Viruses. J Vet Med Sci 2000;62:85-92. https://doi.org/10.1292/jvms.62.85.

[19] Arshad SS. Report: Evaluation of the Shield Aegis Antimicrobial Against H1N9 Avian Influenza Virus. Serdang: 2006.

[20] Dzyakanava V, Burningham K. Report: Determination of the Antiviral Properties of a Novel Antimicrobial Solution Used to Coat Porous Surfaces. Montana: BioScience Laboratories Inc.; 2009.

[21] Caschera A, Mistry KB, Bedard J, Ronan E, Syed MA, Khan AU, et al. Surface- 
attached sulfonamide containing quaternary ammonium antimicrobials for textiles and plastics. RSC Adv 2019;9:3140-50. https://doi.org/10.1039/C8RA10173F.

[22] Shum RL, Liu SR, Caschera A, Foucher DA. UV-Curable Surface-Attached Antimicrobial Polymeric Onium Coatings: Designing Effective, Solvent-Resistant Coatings for Plastic Surfaces. ACS Appl Bio Mater 2020;3:4302-15. https://doi.org/10.1021/acsabm.0c00359.

[23] Tamimi AH, Carlino S, Gerba CP. Long-term efficacy of a self-disinfecting coating in an intensive care unit. Am J Infect Control 2014;42:1178-81. https://doi.org/10.1016/j.ajic.2014.07.005.

[24] Ellingson KD, Pogreba-Brown K, Gerba CP, Elliott SP. Impact of a Novel Antimicrobial Surface Coating on Health Care-Associated Infections and Environmental Bioburden at 2 Urban Hospitals. Clin Infect Dis 2020;71:1807-13. https://doi.org/10.1093/cid/ciz1077.

[25] Torkelson AA, da Silva AK, Love DC, Kim JY, Alper JP, Coox B, et al. Investigation of quaternary ammonium silane-coated sand filter for the removal of bacteria and viruses from drinking water. J Appl Microbiol 2012;113:1196-207. https://doi.org/10.1111/j.1365-2672.2012.05411.x.

[26] Ikner LA, Beck V, Gundy PM, Gerba CP. A Continuously Active Antimicrobial Coating Remains Effective After Multiple Contamination Events. MedRxiv 2020:111. https://doi.org/10.1101/2020.09.07.20188607.

[27] Astuti I, Ysrafil. Severe Acute Respiratory Syndrome Coronavirus 2 (SARS-CoV2): An overview of viral structure and host response. Diabetes Metab Syndr Clin Res Rev 2020;14:407-12. https://doi.org/10.1016/j.dsx.2020.04.020.

[28] Ghosh S, Dellibovi-Ragheb TA, Kerviel A, Pak E, Qiu Q, Fisher M, et al. $\beta$ Coronaviruses Use Lysosomes for Egress Instead of the Biosynthetic Secretory Pathway. Cell 2020;183:1520-1535.e14. https://doi.org/10.1016/j.cell.2020.10.039.

[29] BS EN 16777:2018 Chemical disinfectants and antiseptics. Quantitative nonporous surface test without mechanical action for the evaluation of virucidal activity of chemical disinfectants used in the medical area. London: British Standards Institute; 2018.

[30] Caly L, Druce J, Roberts J, Bond K, Tran T, Kostecki R, et al. Isolation and rapid sharing of the 2019 novel coronavirus (SARS-CoV-2) from the first patient diagnosed with COVID-19 in Australia. Med J Aust 2020;212:459-62. https://doi.org/10.5694/mja2.50569.

[31] Boudewijns R, Thibaut HJ, Kaptein SJF, Li R, Vergote V, Seldeslachts L, et al. STAT2 signaling restricts viral dissemination but drives severe pneumonia in SARS-CoV-2 infected hamsters. Nat Commun 2020;11:5838. https://doi.org/10.1038/s41467-020-19684-y.

[32] Elbe S, Buckland-Merrett G. Data, disease and diplomacy: GISAID's innovative 
contribution to global health. Glob Challenges (Hoboken, NJ) 2017;1:33-46. https://doi.org/10.1002/gch2.1018.

[33] ASTM insternational. ASTM E1053 - 20 Standard Practice to Assess Virucidal Activity of Chemicals Intended for Disinfection of Inanimate, Nonporous Environmental Surfaces. Online 2020.

[34] ASTM E1838 - 17: Standard Test Method for Determining the Virus-Eliminating Effectiveness of Hygienic Handwash and Handrub Agents Using the Fingerpads of Adults. West Conshohocken: ASTM International; 2017. https://doi.org/10.1520/E1838-17.

[35] Porosa L, Caschera A, Bedard J, Mocella A, Ronan E, Lough AJ, et al. UVCurable Contact Active Benzophenone Terminated Quaternary Ammonium Antimicrobials for Applications in Polymer Plastics and Related Devices. ACS Appl Mater Interfaces 2017;9:27491-503. https://doi.org/10.1021/acsami.7b07363. 